\title{
Entecavir for treatment of chronic hepatitis B: A clinical update for the treatment of patients with decompensated cirrhosis ${ }^{*}$
}

\author{
P. Patrick Basu", Robert S. Brown Jr. \\ Department of Medicine, College of Physicians and Surgeons, Columbia University, New York, USA \\ Email: "basu.patrick@gmail.com
}

Received 14 March 2012; revised 12 April 2012; accepted 25 April 2012

\begin{abstract}
The introduction of nucleos(t)ide analogues for the treatment of chronic hepatitis B virus (HBV) infection was transformative in reducing morbidity and mortality. Entecavir, a potent selective nucleoside analogue first approved in 2005 for treatment of chronic HBV, is associated with significant antiviral, biochemical, serologic, and histologic responses. Rapid reductions in HBV DNA levels, low risk of resistance development, and a favorable adverse event profile have contributed to its clinical usefulness. Recent developments in the use of entecavir have increased its utility in the management of difficult-to-treat patients with chronic HBV, including those patients with decompensated liver disease. Recent studies in this population have demonstrated that entecavir $1.0 \mathrm{mg} / \mathrm{d}$ given for up to 48 weeks had superior antiviral activity when compared with adefovir and was generally safe and well tolerated. Long-term outcomes of entecavir in difficult-to-treat populations are eagerly anticipated.
\end{abstract}

Keywords: Aminotransferase; Coinfection; Decompensated Liver Disease; Entecavir; HAART; Hepatitis B Virus; Hepatocellular Carcinoma; Nucleoside Analogue; Resistance

\section{INTRODUCTION}

Chronic hepatitis B virus (HBV) infection affects 350 to 400 million individuals worldwide and 1.25 million in

\footnotetext{
*Financial \& competing interest disclosure: Medical writing and editorial assistance was provided under the direction of P. P. Basu by MedThink Communications with support from Salix Pharmaceuticals, Inc. P. P. Basu has received educational grants from Salix Pharmaceuticals, Inc, and Romark Laboratories, LC, and serves on advisory boards for Roche and Gilead Sciences, Inc. R. S. Brown Jr. has received grant support from Gilead Sciences, Inc., and Bristol-Meyers Squibb and is a consultant for Gilead Sciences, Inc., and Genentech, Inc.

${ }^{\#}$ Corresponding author.
}

the United States [1,2]. North America is considered a low-prevalence $(<2 \%)$ area [3], with pockets of high prevalence (e.g., Asian immigrants, Alaskan natives). However, the prevalence of chronic HBV infection is increasing with the influx of immigrants from Asia, Eastern Europe, and other endemic areas. Chronic HBV infection is characterized by active viral replication and persistence of hepatitis B surface antigen (HBsAg) for $>6$ months with or without hepatitis $\mathrm{B}$ e antigen ( $\mathrm{HBeAg}$ ) (Figure 1) [4]. The natural history of chronic HBV infection varies widely. The majority of patients have some degree of liver injury due to chronic infection, cirrhosis, or end-stage liver disease, and hepatocellular carcinoma (HCC) occurs in approximately $33 \%$ to $40 \%$ of patients [4-6]. Chronic HBV infection is associated with an annual progression rate to cirrhosis of $2 \%$ to $5.5 \%$, and there is a 5 -year cumulative rate of progression of $8 \%$ to $20 \%$ in $\mathrm{HBeAg}$-positive patients and $8 \%$ to $10 \%$ in HBeAg-negative patients [7]. For patients with liver cirrhosis, the mortality risk is higher with both the chance of decompensation of liver function and a substantially higher risk of HCC. The 5-year survival rate for patients with decompensated liver disease and compensated liver disease were $14 \%$ and $84 \%$, respectively [8]. Significant improvements in survival are associated with suppression of HBV replication and biochemical remission. Therefore, antiviral therapy is the mainstay treatment strategy for patients with both compensated and decompensated cirrhosis $[5,9,10]$.

An important goal of treatment is reducing HBV DNA levels to the lowest possible level, thereby reducing liver inflammation and improving biochemical and histologic markers of disease activity $[5,9,10]$. Entecavir (Baraclude $^{\circledR}$; Bristol-Myers Squibb, Princeton, NJ), an orally available guanosine nucleoside analogue, is a potent and selective drug for HBV and has been demonstrated to be safe and effective in nucleoside-naive and lamivudine (Epivir $^{\circledR}$; GlaxoSmithKline, Research Triangle Park, $\mathrm{NC}$ )-refractory patients with $\mathrm{HBeAg}$-positive or $\mathrm{HBeAg}$ negative chronic HBV infection [11-19]. The agent also 


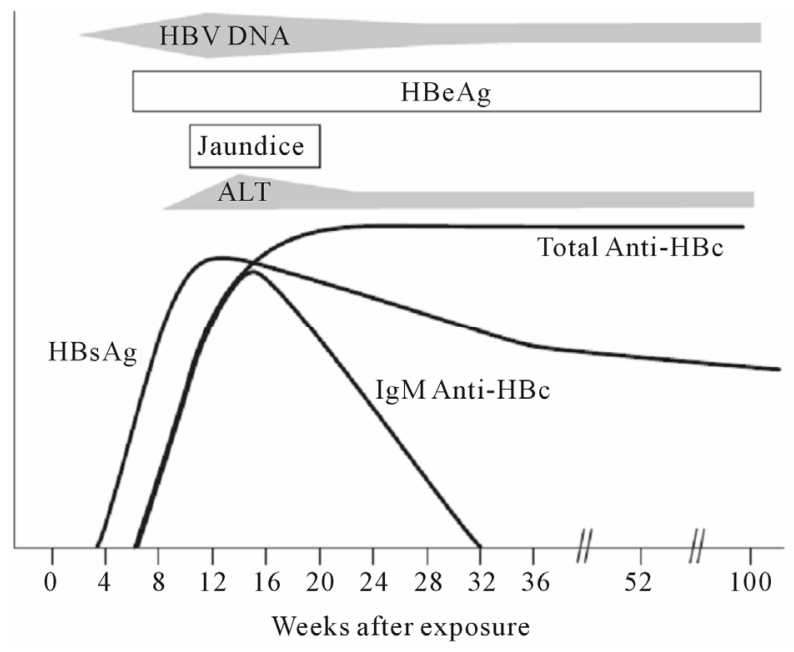

Figure 1. Serologic characteristics of patients with chronic HBV infection [18]. Chronic infection is characterized by active viral replication and persistence of serum $\mathrm{HBsAg}, \mathrm{HBeAg}$, and HBV DNA. HBV DNA levels and serum ALT remain elevated, with a notable proportion of patients developing end-stage liver disease and HCC. Chronic HBV infection is associated with progression to cirrhosis, with associated poor prognosis. ALT, alanine aminotransferase; anti-HBc, hepatitis $\mathrm{B}$ core antibody; $\mathrm{HBeAg}$, hepatitis $\mathrm{B}$ e antigen; $\mathrm{HBsAg}$, hepatitis B surface antigen; HBV, hepatitis B virus; HCC, hepatocellular carcinoma; IgM, immunoglobulin M. Reprinted with permission from Macmillan Publishers Ltd [22], copyright 2009.

has utility in treatment of HIV/HBV coinfected patients if background highly active antiretroviral therapy (HAART) is maintained for HIV suppression [20]. Because entecavir treatment results in rapid reductions in HBV DNA levels and is associated with low long-term rates of resistance, the agent was investigated and later approved for treatment of patients with HBV with decompensated liver disease based on a randomized open-label study comparing entecavir with adefovir $\left(\right.$ Hepsera $^{\circledR}$; Gilead Sciences, Inc., Foster City, CA) [21,22].

\section{ENTECAVIR IN CHRONIC HBV INFECTION}

\subsection{Overview of the Market}

The current treatment for chronic HBV infection in the United States consists of 7 approved treatments, including 2 forms of interferon- $\alpha$ (standard and pegylated) and 5 oral nucleos(t)ide analogues (NAs; Figure 2) $[5,9,10]$. Interferon- $\alpha$ was the first treatment available for chronic HBV infection. Although relatively effective for suppressing viral replication and inducing seroconversion (i.e., $\mathrm{HBeAg}$ and HBsAg loss) [23], the agent is limited by its challenging adverse event (AE) profile and the need for careful patient monitoring [24]. The introduction of pegylated interferon (pegIFN), which requires less-frequent subcutaneous administration, improved the convenience but not the AE profile of interferon-based therapy [5]. Oral NAs have largely supplanted interferon use as a result of their ease of oral administration, low AE profile, and potency [10].

The first NA (i.e., lamivudine) was available in 1998 (Figure 2). Adefovir was later introduced, and though lamivudine and adefovir are effective in suppressing HBV DNA levels, these agents were associated with high rates of resistance development [5]. Because NAs do not have immunomodulatory effects, long-term treatment with these agents is usually required to prevent viral relapse [25]. As a consequence, risk of resistance has emerged as an important consideration in treatment selection. Newer-generation NAs, including entecavir and tenofovir (Viread ${ }^{\mathbb{R}}$; Gilead Sciences, Inc.), are more potent antiviral agents and also have a lower risk of resistance, thereby increasing the benefits of therapy.

\subsubsection{Treatment of HBeAg-Positive and HBeAg-Negative Chronic HBV Infection}

Patients with HBeAg-positive chronic HBV infection should be considered for treatment with 1 of the 7 approved antiviral medications $[5,10]$. Clinical efficacy of these treatments in $\mathrm{HBeAg}$-positive patients is summarized in Table 1 [5,11,26-30]. In general, tenofovir, entecavir, and pegIFN- $\alpha$ are the preferred regimens due to both superior potency and low rates of resistance $[5,9$, 10].

Patients with $\mathrm{HBeAg-negative} \mathrm{chronic} \mathrm{HBV} \mathrm{infection}$ should be considered for treatment. Clinical efficacy of available treatments in $\mathrm{HBeAg-negative} \mathrm{patients} \mathrm{is} \mathrm{sum-}$ marized in Table 2 [5,15,30-33]. As with treatment of $\mathrm{HBeAg}$-positive HBV infection, tenofovir, entecavir, and pegIFN- $\alpha$ are the preferred regimens for patients with HBeAg-negative HBV infection [5,9,10]. Interferon should be not be used in patients with cirrhosis [5] and is contraindicated in patients with decompensated cirrhosis [24] because of the risk of hepatic flares and liver failure [5].

\subsubsection{Treatment of HIV/HBV Coinfection}

Patients coinfected with HIV and HBV who meet criteria for chronic HBV infection should receive treatment for their chronic HBV infection in addition to treatment for HIV $[5,9,10]$. A major consideration is the selection of mutant-resistant treatment, even with agents associated with lower resistance potential. Resistance is an unwelcome development because it is usually associated with rebound in HBV load (or possibly a change in HIV infectivity) and exacerbation of disease [34,35]. According to clinical practice guidelines, patients should initiate treatment for both HIV and HBV infection with agents that are active against both viruses (e.g., lamivudine plus tenofovir or emtricitabine [Emtriva ${ }^{\circledR}$; Gilead Sciences, 


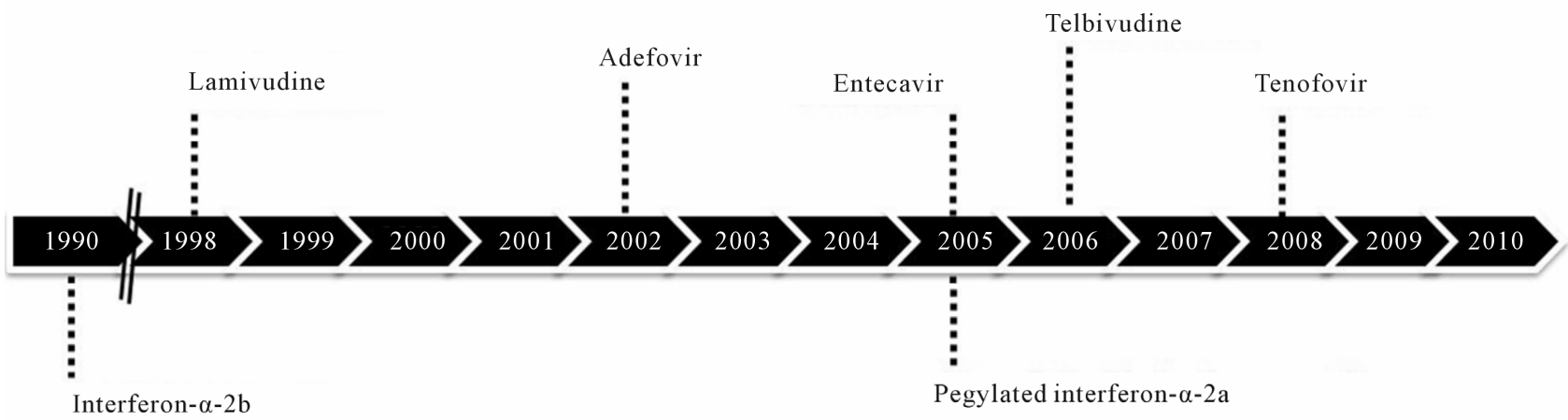

Figure 2. Historical overview of United States-marketed antiviral agents for treatment of chronic hepatitis B. In 1990, interferon- $\alpha-2 b$ became the first drug approved for treatment of chronic HBV infection. It wasn't until 2005 that a pegylated formulation of interferon- $\alpha-2$ a became available with improved pharmacokinetics, safety, and convenience. Lamivudine was the first nucleoside analogue approved (1998), which ushered in a new era of oral therapy for chronic hepatitis B. Entecavir was approved in 2005 for adults with evidence of active viral replication and either evidence of persistent elevations in serum aminotransferases or histologically active disease. Entecavir was most recently approved in 2010 for treatment of patients with decompensated liver disease.

Table 1. Clinical summary of approved agents in HBeAg-positive chronic HBV infection [5,11,26-30].

\begin{tabular}{|c|c|c|c|c|c|c|c|}
\hline Parameter & IFN- $\alpha$ & pegIFN- $\alpha$ & Adefovir & Entecavir & Lamivudine & Telbivudine & Tenofovir \\
\hline Route & Subcutaneous & Subcutaneous & Oral & Oral & Oral & Oral & Oral \\
\hline Dose & $\begin{array}{l}5 \text { MU q.d. or } 10 \\
\text { MU t.i.w. }\end{array}$ & $180 \mu \mathrm{g}$ q.w. & 10 mg q.d. & $0.5 \mathrm{mg}$ q.d. & 100 mg q.d. & 600 mg q.d. & $300 \mathrm{mg}$ q.d. \\
\hline \multicolumn{8}{|l|}{ Efficacy } \\
\hline $\begin{array}{c}\text { Loss of HBV } \\
\text { DNA }\end{array}$ & $37 \%$ & $25 \%-34 \%$ & $21 \%$ & $67 \%$ & $40 \%-44 \%$ & $60 \%$ & $76 \%$ \\
\hline $\begin{array}{c}\text { Normalization of } \\
\text { ALT }\end{array}$ & $23 \%$ & $39 \%$ & $48 \%$ & $68 \%$ & $41 \%-75 \%$ & $77 \%$ & $68 \%$ \\
\hline $\begin{array}{c}\text { Histologic } \\
\text { improvement }\end{array}$ & NA & $38 \%$ & $53 \%$ & $72 \%$ & $49 \%-56 \%$ & $65 \%$ & $74 \%$ \\
\hline $\begin{array}{c}\text { HBeAg } \\
\text { seroconversion }\end{array}$ & $18 \%$ & $27 \%-32 \%$ & $12 \%$ & $21 \%$ & $16 \%-21 \%$ & $22 \%$ & $21 \%$ \\
\hline Loss of HBsAg & $8 \%$ & $3 \%$ & $0 \%$ & $2 \%$ & $1 \%$ & $0 \%$ & $3 \%$ \\
\hline Drug resistance & - & - & $\begin{array}{c}0 \%, \text { yr } 1 \\
29 \%, \text { yr } 5\end{array}$ & $\begin{array}{l}\text { Negligible } \\
1 \%, \text { yr } 5\end{array}$ & $\begin{array}{l}20 \%, \text { yr } 1 \\
70 \%, \text { yr } 5\end{array}$ & $\begin{array}{l}\text { Negligible } \\
25 \% \text {, yr } 2\end{array}$ & $0 \%$, yr 3 \\
\hline Side effects & Numerous & Numerous & Nephrotox & Negligible & Negligible & Negligible & Nephrotox \\
\hline
\end{tabular}

ALT, alanine aminotransferase; HBeAg, hepatitis B e antigen; HBsAg, hepatitis B surface antigen; HBV, hepatitis B virus; IFN- $\alpha$, interferon- $\alpha$; NA, not available; Nephrotox, potential nephrotoxicity; pegIFN- $\alpha$, pegylated interferon- $\alpha$; q.d., once daily; q.w., every week; t.i.w., 3 times weekly.

Table 2. Clinical summary of approved agents in HBeAg-negative chronic HBV infection [5,15,30-33].

\begin{tabular}{cccccccc}
\hline Parameter & IFN- $\boldsymbol{\alpha}$ & pegIFN- $\boldsymbol{\alpha}$ & Adefovir & Entecavir & Lamivudine & Telbivudine & Tenofovir \\
\hline Loss of HBV DNA & $60 \%-70 \%$ & $63 \%$ & $51 \%$ & $90 \%$ & $60 \%-73 \%$ & $88 \%$ & $93 \%$ \\
Normalization of ALT & $60 \%-70 \%$ & $38 \%$ & $72 \%$ & $78 \%$ & $60 \%-79 \%$ & $74 \%$ & $76 \%$ \\
Histologic improvement & NA & $48 \%$ & $64 \%$ & $70 \%$ & $60 \%-66 \%$ & $67 \%$ & $72 \%$ \\
\hline
\end{tabular}

ALT, alanine aminotransferase; HBeAg, hepatitis B e antigen; HBV, hepatitis B virus; IFN- $\alpha$, interferon- $\alpha$; NA, not available; pegIFN- $\alpha$, pegylated interferon- $\alpha$.

Inc.] plus tenofovir). However, up to $90 \%$ of coinfected patients develop resistance to lamivudine at 4 years [36]. Patients with confirmed lamivudine resistance may have tenofovir added to the regimen [5]. Patients who are already receiving HAART with suppression of HIV RNA may receive pegIFN- $\alpha$, adefovir, or entecavir $[5,20]$. 
Importantly, entecavir has been shown to select for the M184V mutation in the HIV virus [5]. Additionally, adefovir should not be used concurrently with tenofovir, and entecavir should not be used with lamivudine or emtricitabine due to cross-resistance.

\subsubsection{Treatment of Decompensated Liver Disease}

Patients with chronic HBV infection with decompensated liver function have a poor prognosis and should be referred for liver transplantation $[5,9,10]$. Treatment should be initiated promptly with an antiviral agent to rapidly reduce viral load and prompt clinical improvement, which may delay or even avoid the need for transplantation. According to guidelines from the American Association for the Study of Liver Diseases, tenofovir and entecavir are the preferred monotherapy regimens [5], but in many cases, physicians may consider starting combination NA treatment to reduce the risk of drug resistance. This approach is not supported by current guidelines and would require the use of 1 nucleoside analogue (lamivudine, telbivudine $\left[\right.$ Tyzeka $^{\circledR}$; Novartis AG, Basel, Switzerland], or entecavir) with 1 nucleotide analogue (adefovir or tenofovir). Entecavir and tenofovir are associated with the lowest risk of drug resistance, and the clinical profile of entecavir has recently been established in this patient group $[22,37,38]$. Other drugs such as lamivudine and adefovir have demonstrated high resistance and nephrotoxicity, respectively [39]. Notably, interferonbased regimens are contraindicated in this population because of the risk of hepatic failure [24].

\subsection{Introduction to the Compound Entecavir}

Entecavir is a once-daily orally available guanosine NA with potent and selective antiviral activity against HBV [21]. Entecavir was first approved in the United States in 2005 for treatment of chronic HBV infection in adults with evidence of active viral replication and either evidence of persistent elevations in serum aminotransferases or histologically active disease. Subsequently, in October 2010, entecavir was approved for treatment of chronic HBV patients with evidence of decompensated liver disease based on results from an open-label, phase $3 b$, comparative trial [22]. In clinical practice, entecavir is used primarily in first-line treatment of chronic HBV infection and in patients with decompensated liver disease. To date, there are more than 130 published clinical experiences for entecavir, and the optimal uses for entecavir and durability of response to the drug continue to be actively investigated.

\section{Pharmacokinetics and Metabolism}

Entecavir exhibits linear pharmacokinetics across the clinical dosing range, with steady-state levels achieved by days 6 to $10[21,40]$. An extended terminal half-life ranging from 128 to 149 hours supports once-daily dosing [21]. Impaired hepatic function does not alter the pharmacokinetics of entecavir, and additionally, coadministration of agents metabolized by hepatic cytochrome P450 enzymes is unlikely to affect entecavir pharmacokinetics. Absorption of oral entecavir is delayed with a standard high-fat or light meal; thus, US dosing recommendations suggest that entecavir be taken on an empty stomach at least 2 hours after the previous meal and 2 hours before the next meal.

Entecavir is excreted unchanged in the urine, with recovery of $62 \%$ to $73 \%$ of the oral dose [21]. In patients with renal impairment (creatinine clearance $<50 \mathrm{~mL} / \mathrm{min}$ ), the dose of entecavir is adjusted and administered at either a lower daily dose or a normal dose less frequently. Because bioavailability of the oral tablets is $100 \%$ that of the oral solution, the 2 forms of delivery may be used interchangeably.

\subsection{Clinical Efficacy in Chronic HBV Infection}

There is a growing body of evidence that entecavir is effective for a wide range of patients infected chronically with HBV, including patients with decompensated liver function $[22,37,38,41,42]$. Studies of entecavir for $\mathrm{HBeAg}$ positive and HBeAg-negative chronic HBV infection and lamivudine-resistant infection formed the basis for initial drug use $[11,15,19]$, followed by demonstration of clinical efficacy in those patients coinfected with HIV and HBV [20].

\subsubsection{Entecavir for the Treatment of HBeAg-Positive and Lamivudine-Refractory Chronic HBV Infection}

The clinical profile of entecavir in patients with $\mathrm{HBeAg}$ positive and lamivudine-refractory chronic HBV infection is reviewed by Scott et al. [43]. In a trial by Chang et al. [11], nucleoside-naive patients with HBeAg-positive chronic HBV infection were randomized to entecavir $0.5 \mathrm{mg} / \mathrm{d}$ or lamivudine $100 \mathrm{mg} / \mathrm{d}$ for 48 weeks. The primary endpoint was histologic improvement at week 48 , defined as a decrease of $\geq 2$ points in Knodell necroinflammatory score without worsening of fibrosis. A significantly higher proportion of entecavir-treated patients achieved histologic improvement compared with lamivudine-treated patients ( $72 \%$ vs $62 \%$, respectively; $P$ $=0.009$ ). Also, entecavir was superior to lamivudine for secondary endpoints, in particular viral suppression. In addition, none of the patients developed resistance to entecavir during the first year of therapy.

In the multicenter EARLY trial, patients with chronic HBV infection were randomized to treatment with entecavir $0.5 \mathrm{mg} / \mathrm{d}$ or adefovir $10 \mathrm{mg} / \mathrm{d}$ for 52 weeks [44]. 
The primary endpoint was mean change from baseline to week 12 in HBV DNA levels. At week 12, mean change from baseline was $-6.23 \log _{10}$ copies/mL in the entecavir group compared with $-4.42 \log _{10}$ copies $/ \mathrm{mL}$ in the adefovir group $(P<0.0001)$. Early reduction in HBV DNA levels at day 10 was predictive of virologic response at week 48 and was higher in entecavir-treated patients than in adefovir-treated patients (entecavir-adefovir difference, $-0.66 \log _{10}$ copies/mL).

Given that loss of HBsAg has been recognized as an important endpoint for chronic HBV therapy because it may closely reflect elimination of HBV infection [45], the efficacy of entecavir in eliminating HBsAg has been evaluated retrospectively [46]. In this study, 5\% of treatment-naive $\mathrm{HBeAg}$-positive patients who received entecavir therapy for up to 96 weeks had elimination of HBsAg compared with $3 \%$ of patients who received lamivudine. These results provide further evidence of the efficacy of entecavir in HBeAg-positive patients.

In patients with lamivudine-refractory chronic $\mathrm{HBV}$ infection, results from a randomized phase 3 trial demonstrated that entecavir $1.0 \mathrm{mg} / \mathrm{d}(\mathrm{n}=141)$ was superior to continuation of lamivudine $100 \mathrm{mg} / \mathrm{d}(\mathrm{n}=145)$ for 52 weeks [17]. Histologic improvement was achieved in $55 \%$ of entecavir-treated patients compared with only $28 \%$ of lamivudine-treated patients $(P<0.0001)$.

\subsubsection{Entecavir for the Treatment of HBeAg-Negative Chronic HBV Infection}

The clinical profile of entecavir in patients with HBeAgnegative chronic HBV infection has been reported in a phase 3 double-blind study [15] and reviewed by Scott et al. [43]. Nucleoside-naive patients with HBeAg-negative chronic HBV infection were randomized to entecavir 0.5 $\mathrm{mg} / \mathrm{d}(\mathrm{n}=296)$ or lamivudine $100 \mathrm{mg} / \mathrm{d}(\mathrm{n}=287)$ for 52 weeks [15]. The primary endpoint was histologic improvement at week 48 , defined as a decrease of $\geq 2$ points in Knodell necroinflammatory score without worsening of fibrosis. A significantly higher proportion of entecavir-treated patients achieved histologic improvement compared with lamivudine-treated patients $(70 \%$ vs $61 \%$, respectively; $P=0.01)$. Entecavir was also superior to lamivudine for the secondary endpoints, including suppression of HBV DNA. No patients developed resistance to entecavir.

\subsubsection{Treatment of HIV/HBV Coinfection}

A notable percentage of patients infected with HIV are also affected by chronic HBV infection, with liver disease representing a frequent cause of death among those patients who are coinfected (44\% of cases) [47]. The clinical profile of entecavir was investigated in 68 patients receiving lamivudine-containing HAART for HIV/ HBV coinfection [20]. Patients were randomized to 24 weeks of entecavir $1.0 \mathrm{mg} / \mathrm{d}(\mathrm{n}=51)$ or placebo $(\mathrm{n}=17)$ and then rolled over into an open-label extension study for another 24 weeks. The primary endpoint was mean change from baseline in HBV DNA levels at week 24. Mean change in HBV DNA levels at week 24 was -3.65 $\log _{10}$ copies $/ \mathrm{mL}$ in entecavir-treated patients compared with $0.11 \log _{10}$ copies $/ \mathrm{mL}$ in placebo-treated patients $(P<$ 0.0001). Entecavir-resistance substitutions (S202C or T184S) were detected in 2 patients over the 48 weeks of treatment; however, no patient experienced virologic breakthrough.

In patients coinfected with HIV and HBV, entecavir must be used in conjunction with antiviral treatment for HIV (i.e., HAART) [43]. Treatment of both HIV and $\mathrm{HBV}$ infections is required to avoid the potential for resistance and to reduce replication of both viruses [48].

\subsubsection{Treatment of Decompensated Liver Disease}

The use of entecavir now extends to difficult-to-treat patients with chronic HBV infection, including those with decompensated liver disease (Table 3) [22,38,41]. In a 48-week study by Liaw et al, entecavir $1.0 \mathrm{mg} / \mathrm{d}$ showed benefits over adefovir $10 \mathrm{mg} / \mathrm{d}$ in terms of mean change in model for end-stage liver disease (MELD) score ( -2.6 vs -1.7 , respectively) and proportion of patients with HBV DNA levels $<300$ copies/mL (57\% vs $20 \%$, respectively $[P<0.0001])$, alanine aminotransferase (ALT) normalization (63\% vs $46 \%$, respectively $[P=0.04])$, and reduction in Child-Turcotte-Pugh (CTP) score $\geq 2$ (35\% vs 27\%, respectively; Figure 3) [22]. Parameters at study entry were similar between groups, and approximately $34 \%$ of patients were lamivudine resistant at entry. Additionally, the cumulative incidence of HCC and mortality rate were numerically lower, though not statistically significantly, for entecavir-treated patients compared with adefovir-treated patients ( $\mathrm{HCC}, 12 \%$ vs $20 \%$, respectively; mortality, $23 \%$ vs $33 \%$, respectively).

In another recent study by Liaw et al. [41], patients with decompensated liver disease were randomized to tenofovir $300 \mathrm{mg} / \mathrm{d}$, emtricitabine $200 \mathrm{mg} / \mathrm{d}$ plus tenofovir $300 \mathrm{mg} / \mathrm{d}$, or entecavir 0.5 or $1.0 \mathrm{mg} / \mathrm{d}$. Although the primary endpoint was safety (i.e., tolerability failure), all treatment groups experienced similar improvement in virologic, biochemical, and histologic parameters. In patients randomized to entecavir, baseline HBV DNA level was $5.9 \log _{10}$ copies/mL, median CTP score was 7 , and median MELD score was 10.5. Lamivudine resistance was observed in 3 patients $(14 \%)$. Of the 22 patients treated with entecavir for 48 weeks, 16 (73\%) achieved HBV DNA levels $<400$ copies/mL and 12 (55\%) achieved normal ALT levels. Additionally, 5 of 12 patients (42\%) achieved a decrease in CTP score of $\geq 2$, and no patient treated with entecavir experienced an increase in CTP score of $\geq 2$. Safety, including renal 
Table 3. Summary of clinical efficacy of entecavir in decompensated HBV cirrhosis.

\begin{tabular}{cccc}
\hline & Liaw et al. [22] & Liaw et al. [41] & Shim et al. [38] \\
\hline No. patients & 100 & 22 & 70 \\
Lamivudine resistant, $\%$ & 34 & 14 & 0 \\
Baseline HBV DNA, log $_{10}$ copies $/ \mathrm{mL}$ & 7.5 & 5.9 & 7.2 \\
Baseline CTP & 8.8 & 7 & 11.5 \\
Baseline MELD score & 17.1 & 10.5 & 89 \\
HBV DNA undetectable, $\%$ & 57 & 73 & 49 \\
$\downarrow$ CTP $\geq 2, \%$ & 35 & 42 & 2.4 \\
Mean MELD score $\downarrow$ & 2.6 & 2.0 & 81 \\
1-y survival, $\%$ & 84 & 91 & 87 \\
\hline
\end{tabular}

CTP, Child-Turcotte-Pugh score; HBV, hepatitis B virus; MELD, model for end-stage liver disease.

HBV DNA levels
$<300$ copies $/ \mathrm{mL}$

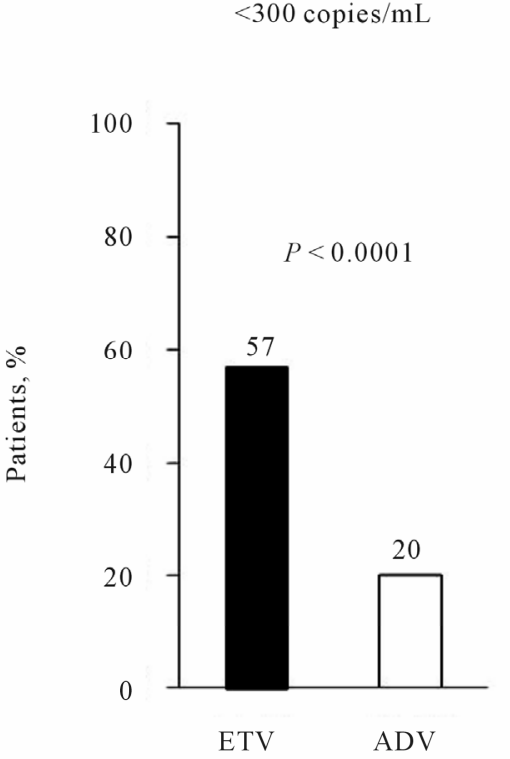

(a)

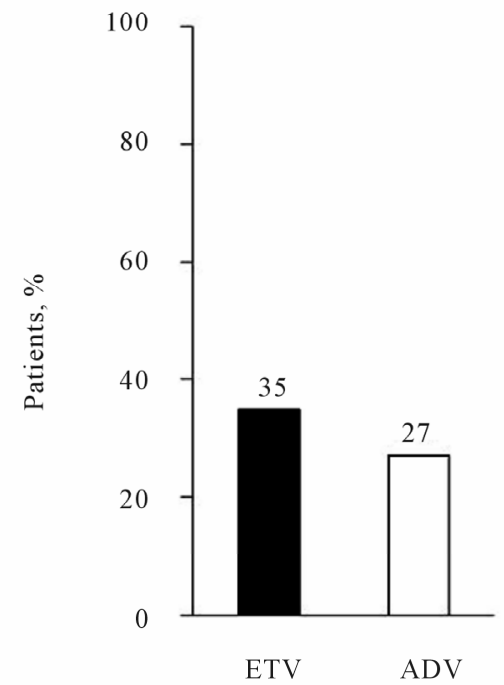

(b)

Figure 3. Efficacy of entecavir in patients with chronic HBV infection and decompensated liver disease [20]. Patients were randomized to entecavir $1.0 \mathrm{mg} / \mathrm{d}(\mathrm{n}=100)$ or adefovir $10 \mathrm{mg} / \mathrm{d}(\mathrm{n}=91)$ for 48 weeks. Although both treatments reduced viral load (a) and improved liver function ((b) and (c)), entecavir demonstrated superior outcomes compared with adefovir. ADV, Adefovir; CTP, Child-Turcotte-Pugh score; ETV, Entecavir; HBV, hepatitis B virus; MELD, model for end-stage liver disease.

safety, was similar with all 3 regimens, and there were no cases of lactic acidosis.

In a study of first-line entecavir $0.5 \mathrm{mg} / \mathrm{d}$ in $70 \mathrm{pa}-$ tients with decompensated cirrhosis (baseline: HBV DNA, $7.2 \log _{10}$ copies/mL; CTP score, 8.4; MELD score, 11.5), HBV DNA was undetectable in $89 \%$ of patients at 1 year [38]. Additionally, 49\% of patients achieved an increase in CTP score of $\geq 2$, and mean MELD score decreased by 2.2. Transplantation-free survival at 1 year was $87 \%$.
Taken together, data from these studies demonstrate the safety and efficacy of entecavir in patients with chronic HBV infection and decompensated liver disease $[22,38,41]$. Entecavir was associated with marked reductions in viral load and improvements in liver function scores. Entecavir extended transplantation-free survival, with overall survival at least equivalent to treatment with other NAs. Longer-term clinical efficacy (and safety) data are needed to more fully characterize the role of entecavir in this population. 


\subsubsection{Long-Term Efficacy of Entecavir in Compensated Liver Disease}

Long-term treatment with entecavir is reviewed by Gonzalez and Keeffe [14]. In a long-term rollover study of HBeAg-positive patients treated with entecavir, 5 years or more of continuous therapy resulted in durable HBV DNA suppression in 94\% of patients and ALT normalization in $80 \%$ of patients [49]. Long-term histologic benefits of entecavir have also been noted. Histologic improvement observed among nucleoside-naive HBeAgpositive and $\mathrm{HBeAg-negative} \mathrm{patients} \mathrm{at} 48$ weeks was continued in patients with long-term biopsy follow-up from 3 to 7 years on therapy (median time of biopsy, 6 years) [13]. Histologic improvement ( $\geq 2$-point decrease in Knodell necroinflammatory score and no worsening of Knodell fibrosis score) was observed in 55 of 57 biopsy samples (96\%). Additionally, all 10 patients with advanced fibrosis or cirrhosis before initiating entecavir achieved histologic improvement.

Risk of entecavir resistance is very low, with a cumulative probability at $1(\mathrm{n}=663), 2(\mathrm{n}=278), 3(\mathrm{n}=149)$, $4(\mathrm{n}=121)$, and 5 years $(\mathrm{n}=108)$ of $0.2 \%, 0.5 \%, 1.2 \%$, $1.2 \%$, and $1.2 \%$, respectively [18]. Cumulative risk of virologic breakthrough was commensurate with risk of resistance, with $0.2 \%, 0.2 \%, 0.8 \%, 0.8 \%$, and $0.8 \%$ of patients experiencing virologic breakthrough at 1, 2, 3, 4, and 5 years, respectively. However, in patients with chronic HBV infection resistant to lamivudine, the 5-year cumulative probabilities of entecavir resistance and entecavir resistance associated with virologic breakthrough were $51 \%$ and $43 \%$, respectively $(n=33)$. Effective treatment options for entecavir-resistant HBV include tenofovir monotherapy [5,50], adefovir monotherapy [5], or combination therapy with entecavir and tenofovir [51].

\subsection{Safety and Tolerability}

Safety and tolerability of entecavir for treatment of chronic HBV infection is reviewed by Scott et al. [43]. In pooled analyses of the pivotal clinical trials conducted in patients with compensated liver function [21], including patients who were nucleoside naive and lamivudine refractory, common AEs included headache, fatigue, and dizziness [35]. Only $1 \%$ of patients enrolled in these trials discontinued entecavir because of an AE or abnormal laboratory result compared with $4 \%$ of lamivudinetreated patients.

In comparative studies of entecavir versus lamivudine $[11,15,19]$ or adefovir [44], incidence and severity of AEs were comparable. Most of the AEs in these trials were mild to moderate in severity, and there were no treatment-related deaths $[11,15,19,44]$.

\section{Safety and Tolerability in Patients with Decompensated Liver Disease}

Common AEs in 102 patients with decompensated liver disease treated with entecavir $1.0 \mathrm{mg} / \mathrm{d}$ included peripheral edema $(16 \%)$, ascites $(15 \%)$, pyrexia (14\%), hepatic encephalopathy $(10 \%)$, and upper respiratory tract infection $(10 \%)$ [21]. Approximately 5\% of patients discontinued over the 48-week period because of AEs. No patient treated with entecavir experienced a hepatic flare over the treatment period. The mortality rate at 48 weeks for patients receiving entecavir was $18 \%$, which was comparable to a mortality rate of $20 \%$ of patients randomized to adefovir.

Lactic acidosis attributable to mitochondrial toxicity may occur in a subset of patients treated with polymerase inhibitors, especially in patients with impaired liver function [52]. Small ( $\leq 16$ patients) retrospective studies in patients with decompensated HBV cirrhosis and high baseline MELD score (i.e., >18) have reported lactic acidosis in patients receiving entecavir $(17 \%$ to $31 \%$ of patients) $[52,53]$, but whether this is a result of the drug itself or hepatic decompensation remains unknown. However, in a 48-week clinical trial of entecavir in patients with decompensated HBV liver cirrhosis, 1 patient who had a baseline MELD score of 21 and no predisposition for lactic acidosis and was receiving entecavir developed lactic acidosis [22]. This instance resolved without treatment or discontinuation of entecavir, suggesting that it may have been unrelated to entecavir.

\section{CONCLUSION}

The progressive nature of chronic HBV infection and potential for downstream complications, including cirrhosis, HCC, and transplantation, indicate a critical need for effective treatments. Because HBV DNA level is correlated with patient outcome, treatments have been directed toward inhibiting HBV replication. Entecavir rapidly and potently reduces HBV DNA levels, which in turn is associated with favorable biochemical and histologic responses. Substantial published evidence suggests that entecavir may be used for the treatment of nucleoside-naive patients with $\mathrm{HBeAg}$-positive or $\mathrm{HBeAg}$ negative chronic HBV infection. Additionally, there is clinical evidence to support entecavir use in HIV/HBV coinfected patients, provided patients are receiving HAART for treatment of HIV infection. Most recently, there is a growing body of data demonstrating favorable efficacy and safety of entecavir in patients with decompensated HBV liver disease.

\section{REFERENCES}

[1] Hepatitis Foundation International (2012) Hepatitis B. 
http://www.hepfi.org/pdfs/Hepatitis/Hepatitis_B-2012.pdf

[2] Hepatitis B Foundation (2012) Statistics. http://www.hepb.org/hepb/statistics.htm.

[3] Carey, W.D. (2009) The prevalence and natural history of hepatitis B in the 21 st century. Cleveland Clinic Journal of Medicine, 76, S2-S5. doi:10.3949/ccjm.76.s3.01

[4] Liang, T.J. (2009) Hepatitis B: The virus and disease. Hepatology, 49, S13-S21. doi:10.1002/hep.22881

[5] Lok, A.S. and McMahon, B.J. (2009) Chronic hepatitis B. Hepatology, 50, 1-36. doi:10.1002/hep. 23190

[6] Bosch, F.X., Ribes, J., Cléries, R. and Diaz, M. (2005) Epidemiology of hepatocellular carcinoma. Clinics in Liver Disease, 9, 191-211. doi:10.1016/j.cld.2004.12.009

[7] Shepherd, J., Gospodarevskaya, E., Frampton, G. and Cooper, K. (2009) Entecavir for the treatment of chronic hepatitis B infection. Health Technology Assessment, 13, 31-36.

[8] de Jongh, F.E., Janssen, H.L., de Man, R.A., Hop, W.C., Schalm, S.W. and van Blankenstein, M. (1992) Survival and prognostic indicators in hepatitis B surface antigen-positive cirrhosis of the liver. Gastroenterology, 103, 1630-1635.

[9] European Association for the Study of the Liver (2009) EASL Clinical Practice Guidelines: Management of chronic hepatitis B. Journal of Hepatology, 50, 227-242. doi:10.1016/j.jhep.2008.10.001

[10] Keeffe, E.B., Dieterich, D.T., Han, S.H., et al. (2008) A treatment algorithm for the management of chronic hepatitis B virus infection in the United States: 2008 update. Clinical Gastroenterology and Hepatology, 6, 1315-1341. doi:10.1016/j.cgh.2008.08.021

[11] Chang, T.T., Gish, R.G., de Man, R., et al. (2006) A comparison of entecavir and lamivudine for HBeAg-positive chronic hepatitis B. New England Journal of Medicine, 354, 1001-1010. doi:10.1056/NEJMoa051285

[12] Chang, T.T., Gish, R.G., Hadziyannis, S.J., et al. (2005) A dose-ranging study of the efficacy and tolerability of entecavir in lamivudine-refractory chronic hepatitis B patients. Gastroenterology, 129, 1198-1209. doi:10.1053/i.gastro.2005.06.055

[13] Chang, T.T., Liaw, Y.F., Wu, S.S., et al. (2010) Longterm entecavir therapy results in the reversal of fibrosis/cirrhosis and continued histological improvement in patients with chronic hepatitis B. Hepatology, 52, 886893. doi:10.1002/hep. 23785

[14] Gonzalez, S.A. and Keeffe, E.B. (2009) Entecavir for the long-term treatment of chronic hepatitis B. Expert Review of Anti-Infective Therapy, 7, 1053-1062. doi:10.1586/eri.09.75

[15] Lai, C.L., Shouval, D., Lok, A.S., et al. (2006) Entecavir versus lamivudine for patients with $\mathrm{HBeAg-negative}$ chronic hepatitis B. New England Journal of Medicine, 354, 1011-1020. doi:10.1056/NEJMoa051287

[16] Schiff, E., Simsek, H., Lee, W.M., et al. (2008) Efficacy and safety of entecavir in patients with chronic hepatitis $\mathrm{B}$ and advanced hepatic fibrosis or cirrhosis. American Journal of Gastroenterology, 103, 2776-2783. doi:10.1111/j.1572-0241.2008.02086.x
[17] Sherman, M., Yurdaydin, C., Sollano, J., et al. (2006) Entecavir for treatment of lamivudine-refractory, $\mathrm{HBeAg}$ positive chronic hepatitis B. Gastroenterology, 130, 20392049. doi:10.1053/j.gastro.2006.04.007

[18] Tenney, D.J., Rose, R.E., Baldick, C.J., et al. (2009) Long-term monitoring shows hepatitis B virus resistance to entecavir in nucleoside-naïve patients is rare through 5 years of therapy. Hepatology, 49, 1503-1514. doi:10.1002/hep.22841

[19] Yao, G., Chen, C., Lu, W., et al. (2007) Efficacy and safety of entecavir compared to lamivudine in nucleoside-naïve patients with chronic hepatitis B: A randomized double-blind trial in China. Hepatology International, 1, 365-372. doi:10.1007/s12072-007-9009-2

[20] Pessôa, M.G., Gazzard, B., Huang, A.K., et al. (2008) Efficacy and safety of entecavir for chronic HBV in HIV/ $\mathrm{HBV}$ coinfected patients receiving lamivudine as part of antiretroviral therapy. AIDS, 22, 1779-1787. doi:10.1097/QAD.0b013e32830b3ab5

[21] Baraclude (package insert) (2010) Bristol-Myers Squibb Company, Princeton.

[22] Liaw, Y.F., Raptopoulou-Gigi, M., Cheinquer, H., et al. (2011) Efficacy and safety of entecavir versus adefovir in chronic hepatitis B patients with hepatic decompensation: A randomized, open-label study. Hepatology, 54, 91-100. doi:10.1002/hep. 24361

[23] Lampertico, P., Del Ninno, E., Manzin, A., et al. (1997) A randomized, controlled trial of a 24-month course of interferon alfa $2 \mathrm{~b}$ in patients with chronic hepatitis $\mathrm{B}$ who had hepatitis B virus DNA without hepatitis B e antigen in serum. Hepatology, 26, 1621-1625. doi:10.1002/hep.510260634

[24] INTRON A (package insert) (2011) Merck \& Co. Inc., Whitehouse Station.

[25] Lee, T.A., Veenstra, D.L., Iloeje, U.H. and Sullivan, S.D. (2004) Cost of chronic hepatitis B infection in the United States. Journal of Clinical Gastroenterology, 38, S144S147. doi:10.1097/00004836-200411003-00005

[26] Lau, G.K., Piratvisuth, T., Luo, K.X., et al. (2005) Peginterferon alfa-2a, lamivudine, and the combination for HBeAg-positive chronic hepatitis B. New England Journal of Medicine, 352, 2682-2695. doi:10.1056/NEJMoa043470

[27] Lai, C.L., Chien, R.N., Leung, N.W., et al. (1998) A one-year trial of lamivudine for chronic hepatitis B. New England Journal of Medicine, 339, 61-68. doi:10.1056/NEJM199807093390201

[28] Lai, C.L., Gane, E., Liaw, Y.F., et al. (2007) Telbivudine versus lamivudine in patients with chronic hepatitis B. New England Journal of Medicine, 357, 2576-2588. doi:10.1056/NEJMoa066422

[29] Marcellin, P., Chang, T.T., Lim, S.G., et al. (2003) Adefovir dipivoxil for the treatment of hepatitis B e antigen-positive chronic hepatitis B. New England Journal of Medicine, 348, 808-816. doi:10.1056/NEJMoa020681

[30] Marcellin, P., Heathcote, E.J., Buti, M., et al. (2008) Tenofovir disoproxil fumarate versus adefovir dipivoxil for chronic hepatitis B. New England Journal of Medicine, 
359, 2442-2455.

[31] Hadziyannis, S.J., Tassopoulos, N.C., Heathcote, E.J., et al. (2003) Adefovir dipivoxil for the treatment of hepatitis B e antigen-negative chronic hepatitis B. New England Journal of Medicine, 348, 800-807. doi:10.1056/NEJMoa021812

[32] Kaymakoglu, S., Oguz, D., Gur, G., et al. (2007) Pegylated interferon alfa-2b monotherapy and pegylated interferon alfa-2b plus lamivudine combination therapy for patients with hepatitis B virus e antigen-negative chronic hepatitis B. Antimicrobial Agents and Chemotherapy, 51, 3020-3022. doi:10.1128/AAC.00088-07

[33] Marcellin, P., Lau, G.K., Bonino, F., et al. (2004) Peginterferon alfa-2a alone, lamivudine alone, and the two in combination in patients with $\mathrm{HBeAg-negative} \mathrm{chronic} \mathrm{he-}$ patitis B. New England Journal of Medicine, 351, 12061217. doi:10.1056/NEJMoa040431

[34] Liaw, Y.F. (2001) Impact of YMDD mutations during lamivudine therapy in patients with chronic hepatitis B. Antiviral Chemistry \& Chemotherapy, 12, 67-71.

[35] Mutimer, D. (2001) Hepatitis B virus infection: Resistance to antiviral agents. Journal of Clinical Virology, 21, 239-242. doi:10.1016/S1386-6532(00)00166-9

[36] Benhamou, Y., Bochet, M., Thibault, V., et al. (1999) Long-term incidence of hepatitis B virus resistance to lamivudine in human immunodeficiency virus-infected patients. Hepatology, 30, 1302-1306. doi:10.1002/hep.510300525

[37] Fontana, R.J. (2010) Entecavir in decompensated HBV cirrhosis: The future is looking brighter. Journal of Hepatology, 52, 147-149. doi:10.1016/j.jhep.2009.10.025

[38] Shim, J.H., Lee, H.C., Kim, K.M., et al. (2010) Efficacy of entecavir in treatment-naïve patients with hepatitis B virus-related decompensated cirrhosis. Journal of Hepatology, 52, 176-182. doi:10.1016/j.jhep.2009.11.007

[39] Zoulim, F., Radenne, S. and Ducerf, C. (2008) Management of patients with decompensated hepatitis $\mathrm{B}$ virus associated cirrhosis. Liver Transplantation, 14, S1-S7. doi:10.1002/1t.21615

[40] Yan, J.H., Bifano, M., Olsen, S., et al. (2006) Entecavir pharmacokinetics, safety, and tolerability after multiple ascending doses in healthy subjects. Journal of Clinical Pharmacology, 46, 1250-1258. doi:10.1177/0091270006293304

[41] Liaw, Y.F., Sheen, I.S., Lee, C.M., et al. (2011) Tenofovir disoproxil fumarate (TDF), emtricitabine/TDF, and entecavir in patients with decompensated chronic hepatitis B liver disease. Hepatology, 53, 62-72. doi:10.1002/hep.23952

[42] Tsai, N., Liaw, Y.F., Raptopoulou-Gigi, M., et al. (2010) Risk and predictors of mortality or hepatocellular carcinoma among entecavir- or adefovir-treated chronic hepatitis B patients with evidence of hepatic decompensation. Gastroenterology, 138, S-831.

\section{doi:10.1016/S0016-5085(10)63831-0}

[43] Scott, L.J. and Keating, G.M. (2009) Entecavir: A review of its use in chronic hepatitis B. Drugs, 69, 1003-1033. doi:10.2165/00003495-200969080-00005

[44] Leung, N., Peng, C.Y., Hann, H.W., et al. (2009) Early hepatitis B virus DNA reduction in hepatitis B e antigen-positive patients with chronic hepatitis B: A randomized international study of entecavir versus adefovir. Hepatology, 49, 72-79. doi:10.1002/hep.22658

[45] Chevaliez, S. and Pawlotsky, J.M. (2008) Diagnosis and management of chronic viral hepatitis: Antigens, antibodies and viral genomes. Best Practice \& Research. Clinical Gastroenterology, 22, 1031-1048. doi:10.1016/j.bpg.2008.11.004

[46] Gish, R.G., Chang, T.T., Lai, C.L., et al. (2010) Loss of HBsAg antigen during treatment with entecavir or lamivudine in nucleoside-naive $\mathrm{HBeAg}$-positive patients with chronic hepatitis B. Journal of Viral Hepatitis, 17, 16-22. doi:10.1111/j.1365-2893.2009.01146.x

[47] Salmon-Ceron, D., Lewden, C., Morlat, P., et al. (2005) Liver disease as a major cause of death among HIV infected patients: Role of hepatitis $\mathrm{C}$ and $\mathrm{B}$ viruses and alcohol. Journal of Hepatology, 42, 799-805. doi:10.1016/j.jhep.2005.01.022

[48] Sorrell, M.F., Belongia, E.A., Costa, J., et al. (2009) National Institutes of Health consensus development conference statement: Management of hepatitis B. Hepatology, 49, S4-S12. doi:10.1002/hep. 22946

[49] Chang, T.T., Lai, C.L., Kew Yoon, S., et al. (2010) Entecavir treatment for up to 5 years in patients with hepatitis $\mathrm{B}$ e antigen-positive chronic hepatitis B. Hepatology, 51, 422-430. doi:10.1002/hep. 23327

[50] Leemans, W.F., Niesters, H.G., van der Eijk, A.A., Janssen, H.L., Schalm, S.W. and de Man, R.A. (2008) Selection of an entecavir-resistant mutant despite prolonged hepatitis B virus DNA suppression, in a chronic hepatitis B patient with preexistent lamivudine resistance: Successful rescue therapy with tenofovir. European Journal of Gastroenterology \& Hepatology, 20, 773-777. doi:10.1097/MEG.0b013e3282f793d6

[51] Petersen, J., Ratziu, V., Buti, M., et al. (2012) Entecavir plus tenofovir combination as rescue therapy in pretreated chronic hepatitis B patients: An international multicenter cohort study. Journal of Hepatology, 56, 520-526.

[52] Lange, C.M., Bojunga, J., Hofmann, W.P., et al. (2009) Severe lactic acidosis during treatment of chronic hepatitis $\mathrm{B}$ with entecavir in patients with impaired liver function. Hepatology, 50, 2001-2006. doi:10.1002/hep.23346

[53] Marzano, A., Marengo, A., Marietti, M. and Rizzetto, M. (2011) Lactic acidosis during Entecavir treatment in decompensated hepatitis B virus-related cirrhosis. Digestive and Liver Disease, 43, 1027-1028. doi:10.1016/j.dld.2011.06.013 